Sérgio Perales

Administrador de Empresas com especialização em Marketing e Gestão de Terceiro Setor. Atua em projetos sociais com foco no desenvolvimento de redes de organizações e processos participativos.

E-mail: sergioperales@uol.com.br.

\title{
VILA BRASILEIRA: UM PROGRAMA PARA PROTAGONISTAS JUVENIS
}

\section{Vilas Brasileiras}

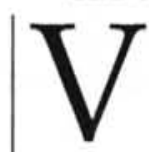

ila Carioca, Vila Edna, Vila Sônia, Vila Liviero, Vila Arapuá, Vila São José, Vila Natália, Vila Nair, Vila Medeiros, Vila Santo Antônio. São Paulo é uma constante de Vilas. Espaços de vida periférica onde mora o perigo, onde persiste a pobreza, onde se despeja o descaso, onde sobrevive a cultura brasileira, feita de pandeiro, gingado e teimosia. Vilas que são uma grande Vila Brasileira.

\section{O que é o Programa Vila Brasileira?}

Um programa de capacitação direcionado a protagonistas juvenis com a finalidade de torná-los empreendedores e multiplicadores culturais. O Programa Vila Brasileira surge a partir de um espaço criado para o aprendizado, a geração de cultura espontânea e a troca de informações e idéias de atuação e produção cultural dentro das comunidades carentes.

\section{Para que serve?}

Para combater a exclusão social e a violência urbana através de ações e processos de capacitação de jovens na utilização da cultura e do espaço urbano como modo de transformação social do indivíduo e da sua comunidade.

\section{Por que?}

Uma cruel realidade é apontada diariamente para um enorme contingente de jovens que não conseguem delinear um horizonte de vida e têm, como provável destino, a delinquiência ou a apatia ante os desafios da vida.

Fazer com que este adolescente direcione a sua energia e identifique outras formas de expressar suas angústias, seus anseios, suas esperanças não é tarefa das mais fáceis. Apesar disto, existem incontáveis casos de jovens protagonistas que conseguiram quebrar as amarras da falta de recursos e informação e produziram cultura de boa qualidade. São gran- 
des exemplos para seus colegas dentro das comunidades em que vivem e podem multiplicar as consciências. Como, por exemplo, a atitude do jovem Ferréz, autor do livro Capão Pecado, ao criar a coluna Literatura Marginal - A Cultura da Periferia, Ato I na revista Caros Amigos, com a função de divulgar a produção literária proveniente da periferia.

Por outro lado, os projetos culturais que o poder público desenvolve não atendem às necessidades de uma massa populacional extremamente carente de lazer e cultura de boa qualidade. Além disso, as leis de incentivo têm um viés demasiadamente elitista. Enquanto alguns eventos culturais podem custar mais de dez milhões de dólares provenientes das leis de incentivo, esta mesma quantia daria para construir mais de 150 centros de geração de cultura bem aparelhados, oferecendo oportunidades de lazer e criação de empregos a um contingente de mais de trezentos mil cidadãos.

\section{Como?}

A partir de um espaço já existente e sendo realizadas amplas reformas e adaptações que possibilitem a sua ocupação, se dá início a uma proposta inovadora de centro de geração de cultura. Este centro tem não somente a finalidade de ensino de artes e ofícios relacionados, mas de capacitação de verdadeiras lideranças comunitárias que se utilizem de projetos de intervenção cultural para modificação e transformação das pessoas, gerando renda ou consciência.

\section{Como este Programa está sendo articulado?}

A realização do Programa Vila Brasileira está sendo efetivada por meio da articulação de uma grande rede de organizações sociais, grupos de jovens protagonistas, por profissionais do setor de produção cultural, educadores e arte-educadores, cidadãos interessados no problema da exclusão cultural e nas comunidades onde o programa está sendo instalado.

Os grupos associativos e redes de organizações sociais são contatados para que identifiquem quais organizações atuam eficientemente com cultura e quais são os jovens e grupos de jovens de suas comunidades com potencial para serem capacitados a reproduzir as intervenções dentro de suas respectivas comunidades.

Escolas que desenvolvem projetos de participação comunitária por meio do conceito de escola aberta servem de base para identificação de jovens com perfil para o Programa Vila Brasileira e com possibilidade de colocação dos mesmos nas monitorias culturais ou como agentes comunitários de cultura.

Também procuramos trabalhar em conjunto com o poder público como forma de criação e formação de políticas públicas para a educação e cultura.

\section{PROJETO PEDAGÓGICO}

O projeto pedagógico do Programa Vila Brasileira passa pelas seguintes etapas:

- Capacitação do jovem tecnicamente na área de sua afinidade

- Capacitação básica em informática, inglês e espanhol

- Discussão do significado de cidadania e de participação comunitária

- Orientação na produção e desenvolvimento de projetos de intervenção cultural e geração de renda 
- Oferta de condições para visualizar oportunidades de ação

- Noções de como interagir com a sua comunidade para a realização de seu projeto

- Habilitação na captação de recursos e gestão do projeto

- Monitoria e orientação contínua da atuação do projeto

\section{AS OFICINAS}

Num primeiro momento as oficinas ministradas dentro do Programa Vila Brasileira são basicamente de:

- Artes plásticas (pintura, desenho, cerâmica, escultura e suas aplicações práticas e comerciais como artesanato, design de pequenos objetos, grafite, estampagem de tecidos, computação gráfica e web design etc.)

- Música (instrumentos, canto, oficinas de disk jóquei, de mixagem e gravação)

- Oficinas de Cinema, Vídeo e Fotografia

- Oficina de Teatro

- Oficina de Literatura

A duração de cada oficina é de um ano de capacitação e um ano para o processo de acompanhamento, quando os alunos participam e criam seminários sobre protagonismo juvenil e outras atividades periódicas na sede.

\section{PROJETO ARQUITETÔNICO}

Para otimizar a ocupação do espaço disponível, a partir da determinação das necessidades de cada projeto de oficina, de comercialização de exposição e seus modos de interação, está sendo elaborado um projeto arquitetônico.

\section{O espaço a ser ocupado}

A idéia surgiu com a oportunidade de utilização de um espaço para projetos socioculturais. Este espaço, a sede do Centro Social Leão XIII, organização social que atua há mais de 40 anos na Vila Maria, está sendo modificado e transformado em um pólo de geração de produtos, eventos e de capacitação de jovens empreendedores culturais provenientes de bairros carentes.

\section{Utilização do espaço}

Durante a semana os espaços são ocupados pelas oficinas e pelo café (lanchonete ou restaurante) e, nos finais de semana, a Vila se transforma em um local de convivência com várias atividades práticas dos alunos ou apresentações de artistas convidados. Tem também lugar para comercialização e exposição dos produtos criados pelos próprios alunos.

\section{Atendimentos}

$\mathrm{O}$ número de jovens que atenderemos no Programa Vila Brasileira é de duzentos jovens ao ano, por unidade. O Programa tem dois focos de atendimento que devem ser equacionados conforme a demanda, através do trabalho com grupos de jovens com perfis empreendedores e protagonistas e da oferta a alunos individualmente.

\section{Inserção no mercado}

O Programa Vila Brasileira tem um setor com a função de descobrir brechas, identificando e criando oportunidades para inserção dos jovens protagonistas no mercado de trabalho cultural. 


\section{Expansão - Projeto Invasão Cultural}

A partir da viabilização da primeira unidade do Programa Vila Brasileira estão sendo iniciadas as ações para expansão do programa, utilizando os inúmeros espaços ociosos em São Paulo. Com a evasão das indústrias da cidade, um grande número de galpões e armazéns encontram-se abandonados e sua ocupação será estudada.

\section{Cronograma de Desenvolvimento de Pré-projeto \\ O início das atividades do Programa} Vila Brasileira se deu em março de 2003. Para sua concretização está sendo necessário seguir o seguinte plano:

Projeto Pedagógico

Projeto de Criação das Oficinas

Projeto de Capacitação Gerencial

Projeto de Inserção Comunitária e

Participação Cidadã

Projeto Arquitetônico

Projeto de Comercialização das Produçōes

Projeto de Eventos

Plano de Custos

Cronograma de Desembolso

Finalização do Plano de Negócios

Captação de Recursos

Projeto de Intervenção e Planejamento

Participativo

Construção

Compra dos Equipamentos

Instalação

Compra de Materiais Diversos

Contratação e Treinamento dos Monitores

Contratação e Treinamento dos

Funcionários

Planificação das Oficinas

Início de Atividades

\section{PROJETO DE INTERVENÇÃO}

O Programa Vila Brasileira é um grupo de projetos integrados de capacitação direcionado a protagonistas juvenis com a finalidade de torná-los empreendedores e multiplicadores culturais. Surgiu com a criação de um espaço voltado para o aprendizado, a geração de cultura espontânea e a troca de informações e idéias de atuação e produção cultural dentro das comunidades carentes.

A nossa missão é combater a exclusão social e a violência urbana através de ações e processos de capacitação de jovens na utilização da cultura e do espaço urbano como modo de transformação social do indivíduo e da sua comunidade.

Devido à complexidade do Programa, está sendo necessário um prévio levantamento de dados e articulação com os atores envolvidos com os objetivos pretendidos. A articulação é realizada com os grupos de jovens protagonistas, lideranças comunitárias, representantes dos órgãos públicos, líderes empresariais, representantes religiosos e das escolas da região.

Foi formada uma Coordenação Geral que tem a finalidade de gerir o processo de Planejamento Estratégico do Programa Vila Brasileira. Como ferramenta de desenvolvimento participativo, foi criada uma lista de discussão na Internet, em que foram convidados a participar, voluntariamente, pessoas que atuam nos vários ramos da atividade cultural e artística e dos setores de suporte para a criação dos projetos. A partir do agrupamento, estão sendo identificados possíveis coordenadores de cada grupo de desenvolvimento para o levantamento de dados ou ações necessárias para a confecção do Programa. 
Para se concluir o Planejamento Estratégico, com os detalhamentos dos processos de implementação, há a necessidade de um processo prévio de diagnóstico de situação. A partir deste diagnóstico, será possível identificar os jovens com perfil para a participação nas oficinas.

Alguns levantamentos estão sendo efetuados, tais como a dimensão das oficinas no que se refere a detalhamento básico de custos, utilização otimizada do espaço disponível e capacidade de atendimento de demanda.

As coordenadorias estão divididas em duas categorias: Oficinas e Suporte.

As Oficinas estão subdivididas em cinco coordenadorias: Teatro, Artes plásticas, Literatura; Cinema, vídeo e fotografia e Música.

As da área de suporte estão subdivididas em sete coordenadorias: Arquitetura, Pedagógico, Produção cultural, Participação comunitária, Comunicação, Eventos e Captação de recursos.

Dentro do Projeto de Intervenção é necessária a participação de um grupo de profissionais altamente qualificados aplicação de processos de desenvolvimento comunitário. Esse levantamento fornece os dados necessários para a finalização do Programa Vila Brasileira e possibilita a conquista da participação da comunidade e da preparação do terreno para a sua implementação.

\section{RECURSOS HUMANOS ENVOLVIDOS NA PESQUISA}

(Remunerados e Voluntários):

\section{Remunerados}

Articulador Comunitário-Alguém que exerça posição de líder comunitário e tenha estreito vínculo com cultura
Coordenador de Pesquisa - Acadêmico com experiência em aplicação de metodologias participativas e pesquisa ação, que coordenará grupo de discentes

Psicopedagogo - Encarregado de apontar caminhos de ação pedagógica que levem à concretização do PVB, em conjunto com o Coordenador de Pesquisa.

Grupo de Planejamento Estratégico Pessoas que determinarão a filosofia e a conceitualização do PVB e coordenarão todas as ações, além de desenvolver o Planejamento Estratégico (parte remunerado).

Coordenadores de Projetos - Profissionais de cada área, tanto das oficinas como das áreas de suporte, atuarão na coordenação dos projetos, na captação de voluntários e na ativação de sua respectiva área dentro da lista de discussão do PVB (talvez remunerados)

\section{Voluntários}

Universitários (Grupo de Pesquisa) Aplicarão os processos de levantamento de dados das ações de sinergia necessárias para a articulação das forças e recursos já existentes na comunidade. Serão supervisionados pelo Coordenador de Pesquisa.

Grupo de Voluntários - Trabalharão nas seguintes atividades:

- Desenvolvimento de projetos a partir de dados fornecidos pela Coordenação Geral

- Participação ativa nas ações locais sob supervisão do pessoal de campo.

\section{ESTRATÉGIA DE APROXIMAÇÃO}

1. Entrar em contato com as organizações da região que trabalhem com jovens e identificar uma pessoa com o perfil para a função de 
Articulador Comunitário. Caso não for encontrado alguém na região, procurar em outros grupos congêneres de outras localidades.

2. Preparar o Articulador Comunitário para passar o conteúdo do Programa Vila Brasileira (PVB) e do projeto de intervenção.

3. O Articulador Comunitário entrará em contato com as outras lideranças dentro da comunidade e começará a articular as várias forças necessárias para o sucesso do projeto de intervenção e do PVB.

4. Reunião entre a Equipe de Intervenção com os Coordenadores de Projetos e a Coordenação Geral, a fim de organizar as atividades conjuntas.

5. Apresentação do PVB, de sua estratégia e da forma de atuação dos grupos de desenvolvimento, para os voluntários.

6. Após a formação do grupo inicial de representantes comunitários e jovens que darão sustentação às ações, apresentá-los ao restante da equipe que coordenará o projeto de intervenção e preparará as primeiras ações.

7. Início das atividades de integração e eventos dentro da comunidade, utilizando os espaços disponíveis e o próprio espaço do PVB.

8. Solucionar os possíveis conflitos ou desvios de rota.

9. Identificar alternativas de ação local e de dados para embasamento dos projetos.

10.Levantamento total de custos dos vários projetos;

11.Finalização do Programa Vila Brasileira (PVB);

12.Ações de captação de recursos;

13. Implementaçãoe início de atividades;

14.Processos de avaliação;

15.Correções; 
Fluxograma

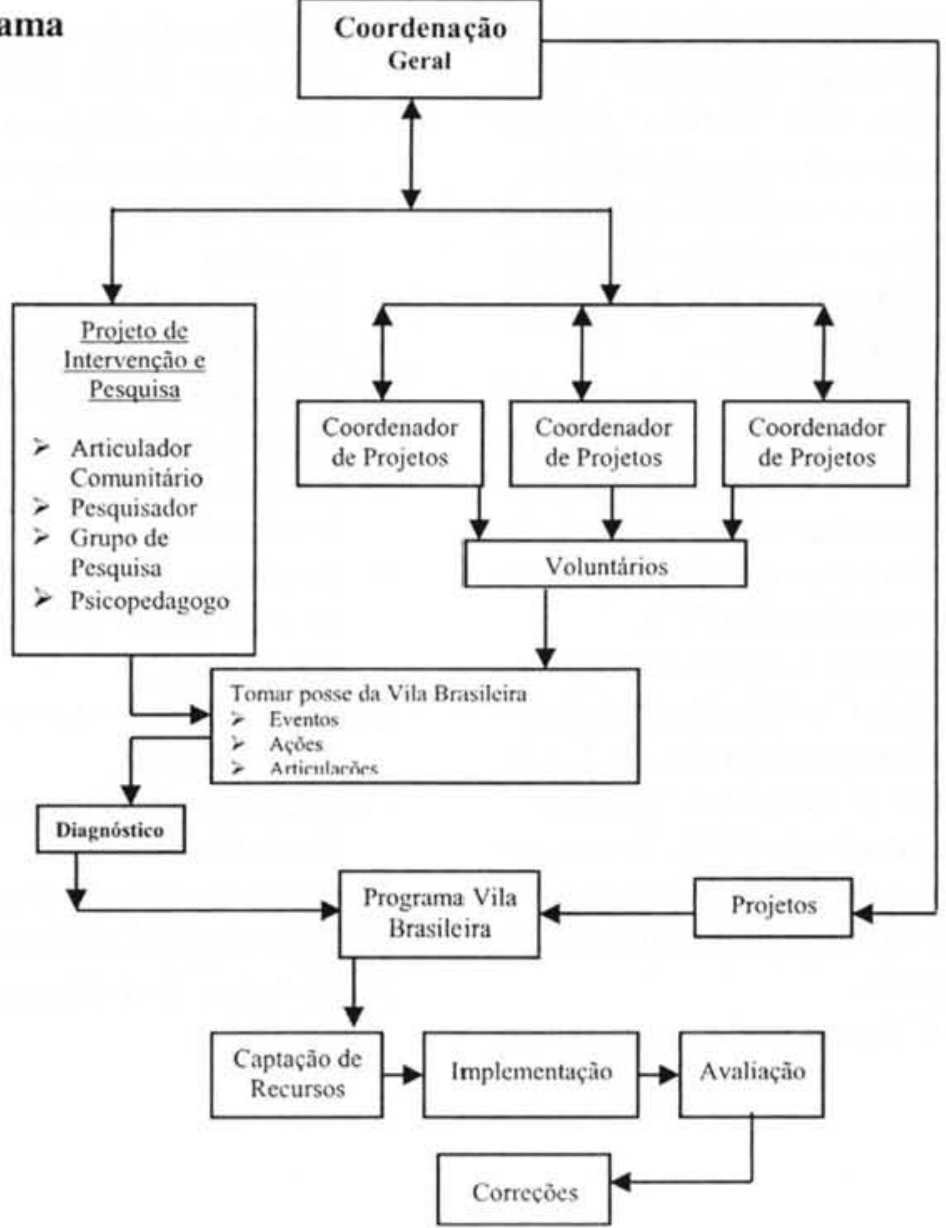

Resumo: O autor apresenta o Programa Vila Brasileira como um grupo de projetos integrados de capacitação direcionado a protagonistas juvenis com a finalidade de torná-los empreendedores e multiplicadores culturais. É um espaço voltado para o aprendizado, a geração de cultura espontânea e a troca de informaçōes, idéias de atuação e produção cultural dentro das comunidades carentes. Com o projeto o autor pretende combater a exclusão social e a violência urbana através de ações e processos de capacitação de jovens na utilização da cultura e do espaço urbano como modo de transformação social do indivíduo e da sua comunidade.

Palavras-chave: protagonistas juvenis, empreendedores, capacitadores, multiplicadores culturais, espaço de aprendizado e produção cultural
(Brazilian Village: a program for juvenile characters)

Abstract. The author presents the Vila Brasileira (Brazilian Village) Program as a group of integrated qualification projects for juvenile characters in order to make them entrepreneurs and cultural multipliers. This is a space aimed at learning, at generating spontaneous culture, and at exchanging performance ideas and cultural production in impoverished communities. With the project, the author intends to combat social exclusion and urban violence through actions and processes to train young people to use culture and the urban space as a mode of social transformation for the individual and his or her community.

Key words: juvenile characters, entrepreneurs, qualifiers, cultural multipliers, space for learning and cultural production 